\title{
REVISITANDO O ESTADO DO CONHECIMENTO SOBRE EDUCAÇÃO A DISTÂNCIA (EAD) EM ADMINISTRAÇÃO: EM QUE SOLO PARADIGMÁTICO ESTAMOS PISANDO?
}

Fernanda Roda Cassundé | fernanda.roda@univasf.edu.br

Mestrado em Administração pela Universidade Federal de Pernambuco. Professora Assistente de Administração da Universidade Federal do Vale do São Francisco, PE.

Nildo Ferreira Cassundé Junior | nildo.cassunde@univasf.edu.br

Mestrado em Economia pela Universidade Federal de Pernambuco.

Professor Assistente da Universidade Federal do Vale do São Francisco, PE.

\section{Resumo}

Admitindo a importância, em termos gerais e em qualquer área, da análise epistemológica na produção do conhecimento científico, e na Administração em termos específicos, este artigo busca analisar a produção de conhecimento de um dos temas que vem ganhando relevância no contexto da produção acadêmica na área: a Educação a Distância (EaD). Assim, procura-se revisitar o estado do conhecimento sobre Educação a Distância em Administração, levantando e analisando os temas/assuntos, demografia de autoria, referências e a base epistemológica de cada artigo. Esta última categoria de análise levou em consideração o trabalho de Burrell e Morgan (1979), que estabelece quatro fronteiras paradigmáticas: funcionalista, interpretativa, humanista radical e estruturalista radical. Os resultados deste estudo podem contribuir para a melhoria da qualidade dos trabalhos elaborados na área.

\section{Palavras-chave}

Estado do conhecimento. Educação a Distância. Análise epistemológica. 


\section{Revisiting the state of knowledge about E-learning in Business Administration: which paradigmatic basis are we treading?}

\section{Abstract}

Admitting the importance, in general terms and in any area of epistemological analysis in the production of scientific knowledge, and specifically in business administration, in specific terms, this article seeks to analyze the production of knowledge of one of the subjects that is gaining relevance in context of academic research in the area, namely, E-learning. Thus, we seek to revisit the state of knowledge about distance education in management, raising and analyzing the topics/issues, demographics of authorship, references and epistemological basis of each article. The latter category of analysis took into account the work of Burrell and Morgan (1979), which sets out four paradigmatic boundaries: functionalist, interpretive, radical humanist and radical structuralism. The results of this study may contribute to improving the quality of work produced in the area.

\section{Keywords}

State of knowledge. E-learning. Epistemological analysis.

\section{Introdução}

As instituições educacionais têm sido motivadas a dinamizar e aprimorar sua forma de transmitir o conhecimento diante dos inúmeros apelos socioeconômicos que têm perpassado o mundo globalizado. Assim, a EaD, nos últimos anos, recebeu apoio inquestionável da tecnologia, cujos instrumentos passaram a dinamizar todo o processo de ensino-aprendizagem e a tornar mais próximo o "contato" através do mundo virtual.
É sabido que a área de Administração figura como uma das pioneiras a oferecer o curso de graduação na modalidade a distância. Diante do avanço dessa modalidade de educação, diversos foram os pesquisadores que direcionaram seus estudos para esta área. Assim, compreender o estado de conhecimento sobre o tema é necessário no processo de evolução da ciência para que seja avaliado constantemente o conjunto de informações e resultados já obtidos, de tal modo que permita indicar possibilidades de integração de diferentes pontos de vista e a determinação de lacunas ou vieses na produção científica.

Nesse sentido, construir um estudo sobre o estado do conhecimento com o propósito de resgatar o que tem sido pesquisado sobre o tema, em especial na área de Administração, permite mapear e identificar as ideias que estão sendo discutidas ao longo dos últimos anos, criando um espaço de discussão sobre a produção científica desta área.

O objetivo deste artigo é identificar os principais temas, autores, tendências de pesquisa $e$ a base epistemológica da área a partir do seguinte questionamento: qual é o estado do conhecimento na produção em Administração sobre Educação a Distância nos artigos publicados em eventos da Associação Nacional de Pós-Graduação e Pesquisa em Administração (ANPAD).

O diferencial deste artigo frente aos demais estudos sobre o estado do conhecimento reside em dois pontos principais: (i) no foco do trabalho, que é em Educação a Distância em Administração; e (ii) no agrupamento das variáveis que, costumeiramente, são analisadas em separado: temática, demografia de autoria e base epistemológica.

Os resultados deste trabalho poderão ser utilizados na análise de tendências da atual e futura produção científica, na discussão dos paradigmas dominantes e emergentes nas Ciências Sociais, contribuindo, assim, para a melhoria da qualidade dos trabalhos elaborados na área. 


\section{Desenvolvimento}

2.1. Por que e para que um estudo sobre o estado do conhecimento?

A "academia em Administração no Brasil tem muitos motivos para comemorar seu desempenho nos últimos anos: sua produção acadêmica aumentou $e$ o acadêmico tem se dedicado mais à pesquisa" (KIRSHBAUM; PORTO; FERREIRA, 2004, p. 7). O aumento das pesquisas organizacionais e administrativas, cuja origem é dada a partir do início da década de 80 , atinge alto grau de desenvolvimento especialmente durante os anos 90 (DAVEL; ALCADIPANI, 2002), proporcionando não apenas a consolidação da Administração como área de conhecimento, com características próprias, como também tem levado a saudáveis reflexões sobre a qualidade da produção científica no campo.

Esse aumento no número de publicações gera, segundo Romanowski e Ens (2006) inquietações e questionamentos como: quais são os temas mais estudados? Que abordagens têm sido utilizadas? Quais as contribuições pertinentes dessas publicações para a área? O que tem sido publicado sobre o tema? Nesse sentido, a partir dos anos 1990 a academia brasileira de Administração parece ter se voltado para si mesma, "em uma análise crítica retrospectiva que busca indagar se, além do evidente crescimento quantitativo, a produção na área cresceu também em qualidade, relevância e originalidade" (CALDAS; TONELLI; LACOMBE, 2002, p. 1). Os metaestudos surgiram e se multiplicaram, analisando a produção científica em cada uma dessas áreas.

A Administração como área de conhecimento vem sofrendo transformações em ritmo muito acelerado; portanto, é necessário monitorar periodicamente o alcance dos estudos desenvolvidos em um período de tempo específico, pois o crescimento quantitativo não necessariamente implica critério de avanço no campo de investigação. Desse modo, Ferreira (2002) e Cardoso et al (2005) destacam a importância de mapear, discutir e conhecer a produção acadêmica em determinada área.
Apesar de reconhecida importância, diversos estudos indicam reduzido número de trabalhos produzidos no país cujo objetivo seja mapear e analisar o conhecimento acumulado em determinada área (TEIXEIRA; MEGID NETO, 2006; CALDAS; TINOCO, 2004). Assim, ao passo que a ciência vai sendo construída ao longo do tempo, privilegiando ora um aspecto, uma metodologia, um referencial teórico, também a análise, em pesquisas de estado do conhecimento produzidas ao longo do tempo deve, de acordo com Soares e Maciel (2000), ser paralelamente elaborada, identificando e explicitando os caminhos da ciência para que seja revelado o processo de construção de conhecimento sobre determinado tema, na tentativa de integrar os resultados e identificar duplicações, contradições e, especialmente, lacunas, ou seja, aspectos ainda não explorados.

\subsection{E lá vem a crise... Os paradigmas $e$ as Ciências} Sociais

Há muito se afirma que o conhecimento científico é representado pela disputa dinâmica e interminável de paradigmas que vão $e$ voltam, somem $e$ transformam-se. Carrieri e Luz (1998) salientam que a questão dos paradigmas, especialmente nas Ciências Sociais, é um dos temas mais importantes quando se busca ir além do estudo das "escolas de pensamento" no sentido de atingir um "patamar de compreensão crítica do que se está produzindo e fazendo a respeito dos fenômenos sociais" (p. 2). Nesse sentido, no campo da Administração, a discussão sobre abordagens paradigmáticas pode ser útil na medida em que provoca os pesquisadores a refletir sobre premissas, práticas e valores comuns em uma comunidade científica (BARBOSA et al, 2012).

Ao retomar o conceito de paradigma em Kuhn (2001) como conjunto de crenças, valores e técnicas compartilhadas por membros de uma determinada comunidade científica, entende-se por que, ao ser aceito pela maioria da comunidade científica, tornase referência obrigatória para abordagens de proble- 
mas de pesquisa. Em outras palavras, os paradigmas são firmados nas necessidades de compartilhamento e transmissão de conhecimento de pessoas que pertencem à mesma comunidade científica $e$, nesse sentido, revelam opções ontológicas, epistemológicas, axiológicas e metodológicas de determinado grupo de pesquisadores (CRESWELL, 2010).

Entretanto, se por um lado os paradigmas norteiam a produção de conhecimento em determinada comunidade científica, por outro eles têm efeitos colaterais negativos como, por exemplo, o fato de imporem limites cognitivos para os pesquisadores e para a produção científica resultante que os adotam, mantendo-os sempre dentro de determinadas fronteiras paradigmáticas (BARBOSA et al, 2012, p. 2).

Neste momento precisamos voltar um pouco à História das Ciências.

As Ciências Humanas (e por que não incluir também as Sociais?) desenvolveram-se a partir da segunda metade do século XIX seguindo o modelo já legitimado pelas Ciências Naturais: o método empregado no campo da natureza parecia ser tão eficaz que não se via razão pela qual não pudesse ser também aplicado também ao ser humano (LAVILLE; DIONE, 1999). Assim, as Ciências Sociais buscaram nas Ciências Naturais sua legitimidade. Recorreram, através da Matemática, ao instrumento de análise, como também à lógica da investigação. Dessa maneira, tinha-se que a construção do conhecimento era resultado da quantificação, ou seja, da divisão, classificação $e$, ainda, da determinação das relações entre o que foi dividido. Era a redução da complexidade. Nesse contexto, o rigor científico seria estabelecido pelo rigor das medições. O que não fosse passível de quantificação tornar-se-ia cientificamente irrelevante (SANTOS, 2000; PLASTINO, 2001).

Nesse sentido, a busca por legitimação a partir de premissas adotadas pelas Ciências Naturais parece ter mostrado às Ciências Sociais um "caminho" diante da necessidade de consolidar cientificamente seus achados; entretanto, transformou esse caminho em uma intrigante encruzilhada: a partir da posição consolidada pelo pensamento dos positivistas, pautando-se em critérios como a objetividade e a neutralidade, tem sido justificado ao longo do tempo o modo de fazer ciência social. Ora, as Ciências Sociais sempre terão um caráter subjetivo, diferentemente das Naturais, que são objetivas e quantificáveis; como será possível, então, conhecer a natureza subjetiva dos fenômenos sociais por meio de processos metodológicos matemáticos? As Ciências Sociais possuem características peculiares, e a forma de fazer ciência a partir das Ciências Naturais gera uma espécie de entrave epistemológico ao avanço do conhecimento científico, por serem (as Ciências Sociais) o objeto em questão (MARTINS, 1996).

Ao refletir a relação entre ambas as Ciências (Naturais e Sociais), poder-se-ia dizer que o caminho não é mais no sentido das Ciências da Natureza em direção às Ciências Sociais, e sim o inverso, partir das Ciências Sociais para as ciências dos fatos naturais. A força do desenvolvimento científico-tecnológico torna o mundo humano de hoje cientificamente estabelecido. Se todo conhecimento humano é social não apenas em sua gênese, mas também nos resultados que gera, somente o conhecimento científico da sociedade permitirá entender a linha de raciocínio do "mundo natural". Dessa forma, o paradigma estabelecido pelas Ciências Naturais não mais representará o discurso, no sentido absoluto, das Sociais, podendo levar à superação do paradigma da ciência moderna, estabelecendo, assim, a transição de paradigmas (SANTOS, 1999).

\footnotetext{
Cada período da história das ideias e dos métodos científicos é reconhecido como um passo necessário no sentindo de uma aproximação cada vez mais apurada de uma descrição do universo considerada como a última verdade a respeito dele. Trata-se, neste caso, da imagem da 'ciência normal'. No entanto, uma análise mais detalhada e mais lúcida da história e da filosofia da ciência nos revelaria uma outra imagem, segundo a qual os avanços obtidos pelas várias disciplinas científicas especializadas não nos aproximam necessariamente de uma descrição mais apurada da realidade (BOEIRA; VIEIRA, 2006, p. 31).
} 
O paradigma das ciências dominante hoje vem passando por uma crise epistemológica, fazendo surgir o paradigma emergente. Essa crise é fundamentada na simplificação da realidade; no rigor matemático, que distancia o cientista do objeto estudado; e, ainda, peca por negligenciar a visão do todo e da relação entre as partes. O que a pós-modernidade propõe e traz para a utilidade prática é uma nova forma de pensar, um exercício de pensamento, uma nova postura científica. Eis, portanto, que o "tal caminho" esbarra em uma crise paradigmática.

De tal modo, essa crise paradigmática promoveu a elaboração de uma série de trabalhos que procuravam delimitar as fronteiras paradigmáticas (BURREL; MORGAN, 1979) e multiparadigmáticas (GIOIA; PITRE, 1990; SCHULTZ; HATCH, 1996; LEWIS; GRIMES, 1999), destacam Silva e Roman Neto (2006).

Assim, a análise de uma determinada realidade pode ser fundamentada em relações e regularidades entre os fenômenos e na procura de leis universais ou na experiência subjetiva dos indivíduos e de como eles criam, modificam e interpretam o mundo.

As discussões epistemológicas, por sua vez, centram-se em duas correntes: o positivismo e o antipositivismo. A primeira é a chamada "mainstream" nas ciências sociais, principalmente na Sociologia, e se caracteriza por procurar explicações mediante a busca de regularidades e de relações causais entre os fenômenos. Seu modelo é o das Ciências Físicas e Naturais transposto para o campo dos fatos sociais. Seu oposto considera que o mundo é essencialmente relativista e só pode ser compreendido do ponto de vista dos atores sociais; portanto, não há como entender o mundo simplesmente como "observador". Desse modo, a ciência não pode gerar qualquer tipo de conhecimento objetivo (CARRIERI; LUZ, 1998, p. 2).

Neste sentido, a contribuição de Burrell e Morgan (1979) é extremamente importante para a Administração porque foram eles os responsáveis por introduzir a noção de paradigma na análise organizacional, revelando os pressupostos subjacentes às teorias sociais em geral e à teoria das organizações em particular (SILVA; ROMAN NETO, 2006). A abordagem desses autores tem implícita em si a ideia de que não apenas divergências científicas, mas também e especialmente divergências filosóficas estabelecem a essência das distinções entre maneiras de análise (ACKROYD, 1992).

A taxonomia criada por Burrell e Morgan (1979) foi baseada em torno das dimensões objetivo/subjetivo sobre a natureza da sociedade e permite classificar como a pesquisa nas organizações exerce sua influência no campo da Administração até os dias atuais (BARBOSA et al, 2012). Em tal taxonomia são definidos quatro paradigmas científicos: funcionalista, interpretativo, humanista radical e estruturalista radical. Burrell e Morgan (1979) consideram a conciliação entre paradigmas cientificamente incorretos, uma vez que eles são contraditórios $e$ mutuamente exclusivos. É importante ressaltar também que o entendimento de paradigma em Burrell e Morgan (1979) é consoante com o entendimento de paradigma em Kuhn (2001), acima exposto. Para os autores, paradigma pode ser definido como "pressupostos metateóricos básicos, que subscrevem um quadro de referência, um modo de teorizar e um modus operandi dos cientistas que operam dentro deles" (BURREL; MORGAN, 1979, p. 23).

É importante salientar que "nem todos os autores concordam com esse esquema classificatório de Burrell e Morgan" (CARRIERI; LUZ, 1998, p. 5). Visões mais contemporâneas, acrescenta Cabral (1998), procuram ir além dessa perspectiva em um esforço de superação (e não de negação), ainda que o trabalho daqueles autores seja seminal.

\section{Design de pesquisa}

Os estudos de estado de conhecimento diferem dos de estado da arte, segundo Romanowski e Ens (2006), porque os primeiros abrangem apenas um setor das publicações sobre o tema estudado, ao passo que os de estado da arte são mais abrangentes, pois não se restringem apenas às teses e dissertações, mas abordam também as produções em congressos e publicações em periódicos da área. 
Apresenta-se uma metodologia de caráter inventariante e descritivo própria dos trabalhos conhecidos como estado do conhecimento e que podem ser caracterizados como estudos bibliométricos (FERREI$R A, 2002)$. A bibliometria, nesse sentido, é uma ferramenta que possibilita o mapeamento e a geração de "diferentes indicadores de tratamento e gestão da informação e do conhecimento, (...) necessários ao planejamento, avaliação e gestão da ciência e da tecnologia de uma determinada comunidade científica ou país" (GUEDES; BORSCHIVER, 2005, p. 15).

A seleção dos artigos para este estudo atendeu aos procedimentos de coleta e análise seguidos por Tonelli et al (2003), que, por sua vez, considerou os mais citados metaestudos nas diversas áreas do EnAnpad, a exemplo de Vieira (1998) e Perin et al (2000). Estes são os critérios adotados:

- Foram recuperados os artigos de eventos organizados pela Anpad. Tais eventos foram escolhidos como corpus para este trabalho tendo em vista a representatividade que essa associação tem em publicações na área de Administração;

- Como horizonte cronológico da pesquisa foi definido o período compreendido entre 1998 e 2011 para estabelecimento do corpus;

- As palavras-chave pesquisadas foram: EaD, educação à(a) distância ${ }^{1}$, ensino à(a) distância, e-learning, ambiente virtual de aprendizagem $e$ ensino on-line.

Após demarcação do universo e a coleta dos artigos, foi possível constituir o corpus da pesquisa, entendido neste estudo como sendo o conjunto dos documentos tidos em conta para serem submetidos aos procedimentos analíticos. $\mathrm{O}$ critério de escolha das categorias definidas para análise seguiu os procedimentos adotados por Caldas e Tinoco (2004).

A partir do referencial epistemológico usado, das metodologias propostas e seguidas e do conteúdo dos

1 "Na expressão educação a distância, pode-se ou não usar a crase, pois ela é facultativa neste caso, sendo obrigatória somente quando define-se a distância, por exemplo: à distância de três metros" (NUNES, 1994, p. 12). trabalhos, procurou-se investigar se estes estavam coerentes com os paradigmas que têm servido às Ciências Sociais como base para seu desenvolvimento. Assim, com relação à variável de base epistemológica, os artigos foram avaliados de acordo com o paradigma preponderante, considerando as definições propostas por Burrell e Morgan (1979) e acompanhando as indicações para esse tipo de análise feita em estudos semelhantes, a exemplo do trabalho de Tonelli et al (2003), que se fundamentou, por sua vez, em Machado-da-Silva, Cunha e Amboni (1990) e em Vieira (1999). Desse modo, cada artigo pode ser categorizado como predominantemente funcionalista, interpretativo, humanista radical e estruturalista radical.

\section{Análise de dados}

\subsection{Por onde caminham os artigos?}

Os artigos foram obtidos em meio digital do site da ANPAD. Alguns trabalhos, embora tenham sido resultado da busca, não conseguiram ser recuperados por problemas internos no servidor da ANPAD. Os artigos foram separados por evento, sendo analisadas pesquisas de onze edições do EnAnpad (Encontro da Associação Nacional de Pós-Graduação e Pesquisa em Administração), três do EnADI (Encontro de Administração da Informação), uma do EnAPG (Encontro de Administração Pública e Governança) e do EnGPR (Encontro de Gestão de Pessoas e Relações de Trabalho) e duas do EnEPQ (Encontro de Ensino e Pesquisa em Administração e Contabilidade) e do Simpósio de Gestão e Inovação Tecnológica, totalizando 48 artigos completos. Das vinte edições de congressos analisadas, apenas uma ocorreu na região Centro-Oeste; foram cinco no Nordeste e a grande maioria (quatorze) no Sul-Sudeste.

A análise de temas dos artigos selecionados foi realizada utilizando a análise de conteúdo dos títulos. Os resultados são demonstrados na Tabela 1 . Os temas foram agrupados em quatro categorias, conforme sugerido por Carneiro e Wrobel (2011): aspectos pedagógicos, aspectos tecnológicos, aspectos sociológicos e aspectos gerenciais. 
Tabela 1: Temas mais frequentes no titulo dos artigos

\begin{tabular}{|c|c|c|c|}
\hline & Temas & Subtotal & Total \\
\hline \multirow{11}{*}{ Aspectos pedagógicos } & Aplicações de $\mathrm{EaD} /$ relato de experiências & 13 & \multirow{11}{*}{35} \\
\hline & Avaliação & 4 & \\
\hline & Tutoria/docência & 3 & \\
\hline & Didática/metodologia de EaD & 2 & \\
\hline & Interação/mediação & 1 & \\
\hline & Modalidade presencial $\mathrm{x}$ a distancia & 4 & \\
\hline & Material didático & 1 & \\
\hline & Objetos de aprendizagem & 1 & \\
\hline & Desenvolvimento de competências & 4 & \\
\hline & Qualidade & 1 & \\
\hline & Afetividade & 1 & \\
\hline \multirow{2}{*}{ Aspectos tecnológicos } & Uso de tecnologias/ferramentas educacionais & 4 & \multirow{2}{*}{13} \\
\hline & Ambiente virtual de aprendizagem & 9 & \\
\hline \multirow{2}{*}{ Aspectos sociológicos } & Formação continuada/formação de professores & 4 & \multirow{2}{*}{6} \\
\hline & Universidade/educação corporativa & 2 & \\
\hline \multirow{3}{*}{ Aspectos gerenciais } & Planejamento/implementação & 5 & \multirow{3}{*}{10} \\
\hline & Gestão do curso & 3 & \\
\hline & Estrutura & 2 & \\
\hline \multicolumn{3}{|c|}{ TOTAL } & 64 \\
\hline
\end{tabular}

Fonte: Elaboração do autor

Como foi possível identificar dois ou mais temas em um mesmo título, o total da Tabela 1 (64) é superior ao número total de artigos selecionados (48). Chama atenção a quantidade de temas relacionados a aplicações de $\mathrm{EaD}$ ou relato de experiências (13), o que pode ser um indício de que a discussão ainda está pautada no nível da experiência individual de cada pesquisador e não de questões mais específicas sobre a $\mathrm{EaD}$, como a questão da interação e mediação da aprendizagem ou do material didático utilizado.

A análise da autoria dos artigos mostra que $41,67 \%$ apresentam entre um e dois autores; entretanto, é também significativa a quantidade de artigos que apresentam três ou mais autores (25\%).

Os estudos a respeito de EaD voltados para a academia são a maioria $(49,99 \%)$. Os relacionados à Educação Profissional também são representativos
(33,33\%); no entanto, $14,58 \%$ dos artigos não puderam ter seu conteúdo classificado por não especificarem de qual nível de ensino a pesquisa tratava.

A Tabela 2 mostra os autores com maior número de publicações e suas instituições de origem (como o modelo de publicação da Anpad não exige a identificação institucional dos autores, recorreu-se à base de dados do Currículo Lattes do CNPq para identificar a filiação dos autores na época da publicação no evento). O que chama atenção é o fato de que, dentre os 48 artigos analisados, o autor que mais publicou tem apenas quatro artigos e que é grande a quantidade de autores com dois ou apenas um artigo publicado. Pode-se perceber que as publicações são isoladas, que a maioria do autores não deu continuidade aos trabalhos de pesquisa sobre o tema analisado. 
Tabela 2: Principais autores

\begin{tabular}{|c|c|c|}
\hline Luis Roque Klering & Universidade Federal do Rio Grande do Sul & 4 \\
\hline Angilberto Sabino de Freitas & Universidade do Grande Rio & 3 \\
\hline Liliana Vasconcellos Jacobsohnn ${ }^{2}$ & - & 3 \\
\hline Marina Keiko Nakayama & Universidade Federal de Santa Catarina & 3 \\
\hline Alberto Luiz Albertin & Fundação Getulio Vargas - SP & 2 \\
\hline Maria José Carvalho de S. Domingues & Universidade Regional de Blumenau & 3 \\
\hline Maria Tereza Leme Fleury & Escola de Administração de São Paulo & 2 \\
\hline Hélène Bertrand & Pontifícia Universidade Católica do Rio de Janeiro & 2 \\
\hline Mauricio Gregianin Testa & Universidade Católica do Rio Grande do Sul & 2 \\
\hline
\end{tabular}

Fonte: Elaboração do autor

Com relação à filiação dos autores, $37,5 \%$ são de universidades do sul (Universidade Federal do Rio Grande do Sul e Universidade Federal de Santa Catarina).

As análises que se seguem dizem respeito às referências bibliográficas utilizadas nos artigos. A primeira análise feita foi em relação às referências dos artigos recuperados para estudo. Foram contabilizadas 1.194 referências completas que serviram de base para análises posteriores. De acordo com as informações da Tabela 3, pode-se verificar que, em média, houve pequena variação na quantidade de referências por artigo nos diversos eventos da Anpad (entre 17,88 e 28,33 referências por artigo). No entanto, os resultados para o Simpósio de Gestão e Inovação Tecnológica não seguem a média dos outros eventos, pois a média de referências por artigo para esse evento foi de 43,5, muito superior à dos demais eventos da Anpad.

2 Não foi identificado o Currículo Lattes da autora na base de dados do CNPq. 
Tabela 3: Quantidade de referências por evento da Anpad e média de referências por artigo

\begin{tabular}{l|c|c|c}
\multicolumn{1}{c|}{ Evento Anpad } & $\begin{array}{c}\text { Quantidade de } \\
\text { referências }\end{array}$ & $\begin{array}{c}\text { Média por } \\
\text { artigo }\end{array}$ & Quantidade de artigos \\
\hline $\begin{array}{l}\text { EnAnpad - Encontro da Associação Nacional de Pós- } \\
\text { Graduação e Pesquisa em Administração }\end{array}$ & 725 & 25 & 06 \\
\hline EnADI - Encontro de Administração da Informação & 170 & 28,33 & 01 \\
\hline $\begin{array}{l}\text { EnAPG - Encontro de Administração Pública e Go- } \\
\text { vernança }\end{array}$ & 24 & 24 & 02 \\
\hline $\begin{array}{l}\text { EnGPR - Encontro de Gestão de Pessoas e Relações } \\
\text { de Trabalho }\end{array}$ & 45 & 22,5 & 08 \\
\hline $\begin{array}{l}\text { EnEPQ - Encontro de Ensino e Pesquisa em Adminis- } \\
\text { tração e Contabilidade }\end{array}$ & 143 & 17,88 & 02 \\
\hline Simpósio de Gestão e Inovação Tecnológica & 87 & 43,5 & $\mathbf{4 8 , 8 8}$ \\
\hline TOTAL & $\mathbf{1 . 1 9 4}$ & $\mathbf{4 8}$ \\
\hline
\end{tabular}

Fonte: Elaboração do autor

$\mathrm{Na}$ Tabela 4 são apresentadas as principais obras referenciadas nos artigos a respeito da discussão sobre EaD. Vale a pena chamar atenção para o fato de que, das 1.194 referências, a obra que mais foi citada nos artigos foi a de Belloni, com 14 observações, o que representa apenas $1,17 \%$ do total de referências utilizadas. O que se pode perceber é que existe dispersão das obras utilizadas, não havendo ainda um quadro de referência em EaD na área de Administração.

Tabela 4: Principais obras referenciadas para discussão sobre EaD

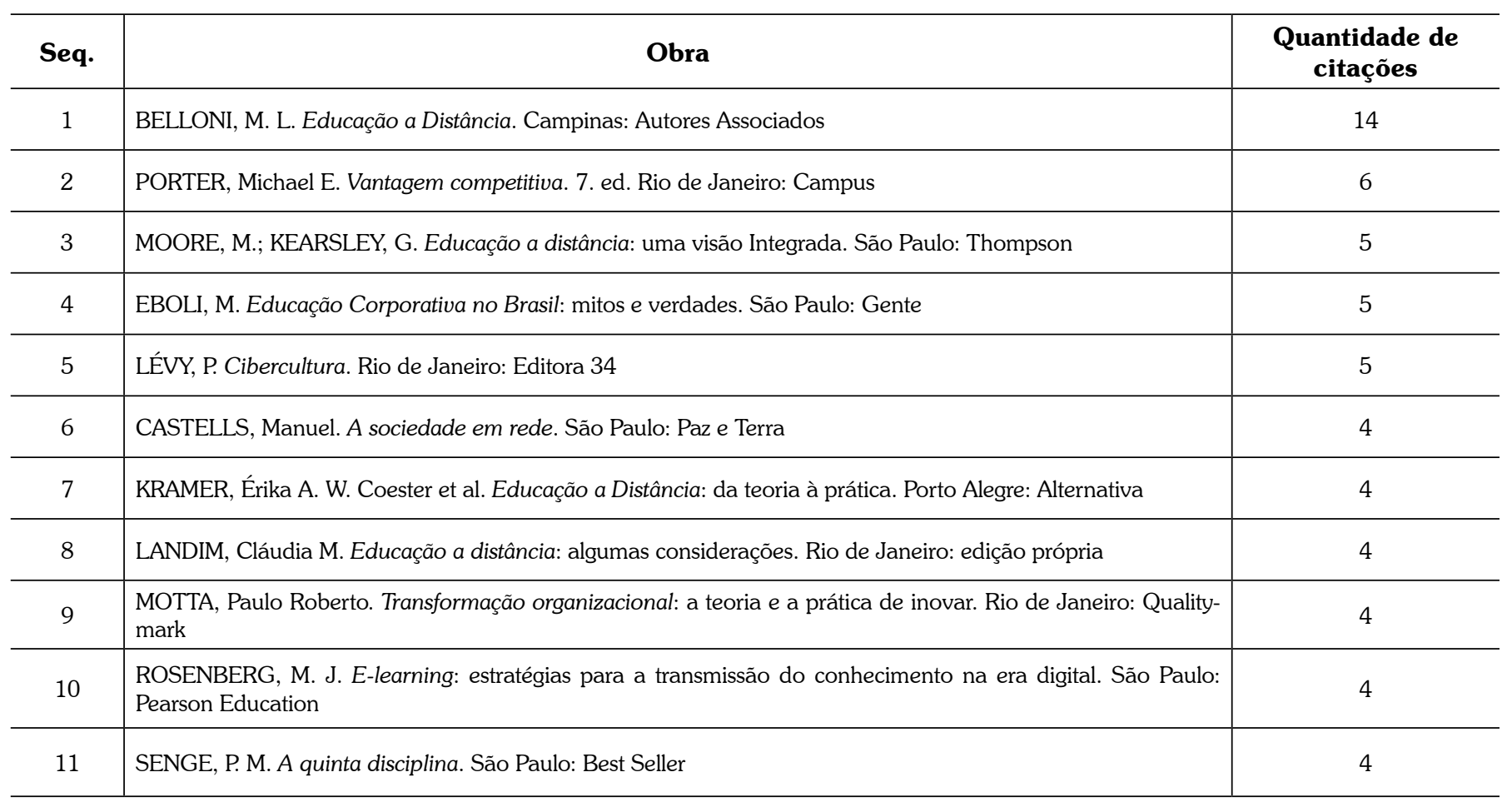

Fonte: Elaboração do autor 
Foram também levantadas informações referentes a trabalhos de conclusão de curso na área de $\mathrm{EaD}$ (quantidade de referências a trabalhos de conclusão de curso, principais IES de origem dos trabalhos de conclusão de curso e principais áreas desses trabalhos). Dos 26 trabalhos de conclusão de curso referenciados nos artigos, 15 são dissertações de mestrado e 11 são teses de doutorado. No entanto, representam apenas $2,43 \%$ de todas as fontes utilizadas. A maior parte desses trabalhos está vinculada à Universidade Federal de Santa Catarina $(46,15 \%)$ e é oriunda da área de Engenharia de Produção (46,15\%). A área de Administração como produtora de teses e dissertações representa $42,31 \%$ das referências utilizadas.

\subsection{Em que solo paradigmático estamos pisando?}

A base epistemológica traz consigo tanto a discussão sobre os pressupostos paradigmáticos do estudo quanto sobre a metodologia utilizada. Nesse sentido, método é um conjunto de procedimentos ou de meios de pesquisa conscientemente moldados ao estudo de um determinado objeto.

Com base nos artigos analisados, não foi possível extrair qualquer orientação paradigmática explícita nas diversas pesquisas, em função da ausência de informações concretas que fundamentassem as conclusões deste trabalho. Assim, os artigos não puderam ser classificados de acordo com a proposta de Burrell $e$ Morgan (1979) em funcionalista, interpretativo, humanista radical ou estruturalista radical.

Apesar de a comunidade científica perceber os paradigmas dominantes como referenciais que permitem apenas uma compreensão parcial dos fenômenos (CABRAL, 1998), parece haver dominância do paradigma funcionalista - cujas bases remontam ao positivismo - nas pesquisas sobre Educação a Distância em Administração. Os artigos privilegiaram o estabelecimento de varáveis (e algumas vezes hipóteses) para a explicação dos fatos, bem como a avaliação das relações existentes entre eles. Nesse sentido, corrobora- -se com Martins (1996, p. 8), que compreende que as pesquisas classificadas como positivistas fazem uso, essencialmente, de técnicas descritivas de investigação (presentes nos artigos analisados), ou seja, "buscam a descrição das características de determinada população ou fenômeno, bem como o estabelecimento de relações entre variáveis e fatos". Entretanto, conforme salienta Cabral (1998, p. 8), essa "restrição à exploração de enfoques fora da perspectiva positivista-funcionalista dominante não é absoluta (...). Ela representa a perpetuação de uma supremacia e não uma total hegemonia", apenas. Essa predominância do funcionalismo definiu um monólogo de uma elite de pensadores no sentido de ver a realidade, estabelecendo a concepção de homem-mundo.

A análise geral dos artigos atenta para as dificuldades de crescimento de um campo de estudo focado em poucas obras e com fundamentos epistemológicos restritos e não explicitados. Aponta a necessidade de propor pesquisas que, ao utilizar diferentes pressupostos epistemológicos, sejam capazes de descrever o fenômeno de maneira mais precisa, cooperando para uma compreensão mais reflexiva do objeto em estudo. Carrieri e Luz (1998) apontam uma série de autores (Reed, Guillén, Clegg e Hardy) ao afirmar que o paradigma dominante tem se mostrado insuficiente ou incapaz de encaminhar soluções satisfatórias para os problemas que se têm apresentado aos pesquisadores, sendo o momento atual propício para a mudança paradigmática.

Nesse sentido, Tonelli et al (2003, p. 120) chama atenção para o fato de que a baixa "diversidade epistemológica, por sua vez, é preocupante, pois, ao escolher uma base eminentemente funcionalista, a área se alinha em escolha com a produção internacional do campo, mas não se posiciona como produtora de conhecimento", restando-lhe apenas ser coadjuvante e reprodutora daquilo que é produzido e pensado internacionalmente. Assim, pode-se dizer que os paradigmas são capazes de oferecer diversas maneiras de investigar o mundo social, impondo escolhas em razão do assunto ou questão proposta, de modo que nenhum deles pode ser classificado como o melhor (CABRAL, 1998). 


\section{Consideraçóes finais}

Este trabalho se propôs a revisitar o estado da arte das publicações sobre $\mathrm{EaD}$ em Administração nos eventos organizados pela Associação Nacional dos Programas de Pós-Graduação em Administração entre os anos de 1998 e 2011.

O que se pode perceber das análises é que não há predominância de publicações em nenhum dos eventos específicos da Anpad; no entanto, a maioria dos artigos trata dos aspectos pedagógicos da Educação a Distância sendo aplicados na Educação Profissional (como aplicações de $\mathrm{EaD}$ /relato de experiências, avaliação, modalidade presencial $\mathrm{x}$ a distância e desenvolvimento de competências). Com relação ao campo epistemológico, não há qualquer orientação paradigmática explícita nas diversas pesquisas; no entanto, parece haver predominância do paradigma funcionalista, pois os artigos privilegiam o estabelecimento de varáveis (e algumas vezes hipóteses) para a explicação dos fatos bem como a avaliação das relações existentes entre eles.

Os artigos são apresentados, em sua maioria, por três ou mais autores, sugerindo que possa haver grupos de pesquisa produzindo e publicando sobre o tema. Porém ficou bastante claro que não há continuidade de produção/publicação por parte dos autores como também uma forte concentração de artigos em poucos centros de pesquisa. Assim, com base nesses dados, não foi possivel identificar uma elite de pesquisadores responsáveis por um volume de produção científica sobre Educação a Distância em Administração.

É importante ressaltar que, em função das limitações deste estudo - considerar apenas os eventos organizados pela Anpad; o período de tempo analisado (embora tenha sido contemplado todo o acervo digital disponível dos eventos) -, os resultados aqui apresentados não podem ser generalizados para outros eventos ou periódicos. Esses resultados dizem respeito aos padróes dos eventos da Anpad. Entretanto, por serem eventos internacional e academicamente reconhecidos, este trabalho tem condições de contribuir para a compreensão da produção científica $e$ do campo epistemológico sobre Educação a Distância em Administração.

Como sugestão a pesquisas futuras, recomendase a avaliação da produtividade dos autores $e$ a verificação não apenas da formação de redes como também dos grupos de pesquisa; tal cenário pode permitir o entendimento da ausência de publicações regulares na área dos autores e a falta de pesquisas de caráter longitudinal na área.

\section{Referências}

ACKROYD, S. Paradigms lost: paradise regained? In: REED, M.; HUGHES, M. Rethinking organization: new directions in organization theory and analysis. London: Sage, 1992.

BARBOSA, Milka Alves C.; NEVES, Flávio Egídio B.; SANTOS, Jouberte Maria L.; CASSUNDÉ, Fernanda Roda S.A.; CASSUNDÉ JUNIOR, Nildo Ferreira. "Positivismos" versus "Interpretativismos": o que a Administração tem a ganhar com esta disputa? In: XXXVI Encontro dos Programas de Pós-Graduação em Administração, 2012, Rio de Janeiro, RJ. Anais... Rio de Janeiro: Anpad, 2012.

BERTERO, C. O.; KEINERT, T. M. M. A evolução da análise organizacional no Brasil (1961-93). Revista de Administração de Empresas, v. 34, n. 3, p. 81-90, maio/ jun. 1994.

BOEIRA, Sérgio Luís; VIEIRA, Paulo Freire. Estudos organizacionais: dilemas paradigmáticos e abertura interdisciplinar. In: GODOI, Christiane Kleinubing; BANDEIRA-DE-MELLO, Rodrigo; SILVA, Anielson Barbosa. Pesquisa qualitativa em estudos organizacionais: paradigmas, estratégias e métodos. São Paulo: Saraiva, 2006. 
BURRELL, G.; MORGAN, G. Sociological paradigms and organisational analysis: elements of the sociology of corporate life. London: Heinemann, 1979.

CABRAL, Augusto Cesar de Aquino. Reflexões sobre a pesquisa nos estudos organizacionais: em busca da superação da supremacia dos enfoques positivistas. In: XXII Encontro dos Programas de Pós-Graduação em Administração, 1998, Foz do Iguaçu. Anais... Foz do Iguaçu: Anpad, 1998.

CALDAS, Miguel; TONELLI, Maria José; LACOMBE, Beatriz Maria Braga. Espelho, espelho meu: metaestudo da produção científica em Recursos Humanos nos EnAnpads da década de 90. In: XXVI Encontro dos Programas de Pós-Graduação em Administração, 2002, Campinas. Anais... Campinas, São Paulo: Anpad, 2002.

CALDAS, Miguel P.; TINOCO, Tatiana. Pesquisa em gestão de recursos humanos nos anos 1990: um estudo bibliométrico. Revista de Administração de Empresas [online]. 2004, v. 44, n. 3, p. 100-114. Acesso em: 11 nov. 2011.

CARDOSO, R. L.; MENDONÇA NETO, O. R.; RICCIO, E. L.; SAKATA, M. C. G. Pesquisa científica em contabilidade entre 1990 e 2003. Revista de Administração de Empresas. São Paulo, v. 45, n. 2, p. 34-45, abr/jun 2005.

CARNEIRO, Teresa Cristina Janes; WROBEL, Julia Schaetzle. Pesquisa em educação a distancia: análise dos anais dos dois principais congressos no Brasil. In: VIII Congresso Brasileiro de Ensino Superior a Distância, Ouro Preto, outubro de 2011.

CARRIERI, Alexandre P.; LUZ, Talita R. Paradigmas e metodologias: não existe pecado do lado debaixo do Equador. In: XXII Encontro dos Programas de Pós-Graduação em Administração, 1998, Foz do Iguaçu. Anais... Foz do Iguaçu: Anpad, 1998.

CRESWELL, J. W. Projeto de pesquisa: métodos qualitativo, quantitativo e misto. $3^{\mathrm{a}}$ ed. Porto Alegre: Artmed/Bookman, 2010.

DAVEL, Eduardo; ALCADIPANI, Rafael. Estudos críticos em Administração: reflexões e constatações sobre produção brasileira. In: Encontro de Estudos Organizacionais, 2002, Recife. Anais... Recife: Observatório da Realidade Organizacional: PROPAD/UFPE: Anpad, 2002.

FERREIRA, Norma Sandra de Almeida. As pesquisas denominadas "estado da arte". Educação \& Sociedade, ano XXIII, n. 79, ago. 2002.

GUEDES, Vânia; BORSCHIVER, Suzana. Bibliometria: uma ferramenta estatística para a gestão da informação e do conhecimento em sistemas de informação, de comunicação e de avaliação científica e tecnológica. In: Proceedings Cinform - Encontro Nacional de Ciência da Informação, Salvador - Bahia, 2005. Disponível em: < http://dici.ibict.br/archive/00000508/>. Acesso em: 14 nov. 2011.

KIRSHBAUM, Charles; PORTO, Elvio Corrêa; FERREIRA, Fernando Coelho Martins. Neoinstitucionalismo na produção acadêmica em Administração. RAE-Eletrônica, v. 3, n. 1, art. 12, maio/jun. 2004.

KUHN, Thomas S. A estrutura das revoluções científicas. São Paulo: Perspectiva, 2001.

LAVILLE, Christian; DIONNE, Jean. A construção do saber: manual de metodologia da pesquisa em ciências humanas. Porto Alegre: Artmed, 1999.

MACHADO-DA-SILVA, Clóvis L., CUNHA, Vera C., AMBONI, Nério. Organizações: o estado da arte da produção acadêmica no Brasil. In: XIV Encontro dos Programas de Pós-Graduação em Administração, 1990, Florianópolis. Anais... Florianópolis: Anpad, 1990. 
MORGAN, G. Paradigmas metáforas e resolução de quebra-cabeças na teoria das organizações. In: BERTERO, Carlos Osmar; CALDAS, Miguel P. Teoria das organizações. RAEClássicos. São Paulo: Atlas, 2007.

NUNES, Ivônio Barros. Noções de Educação a Distância. Revista de Educação a Distância. n. 4/5, dez./93abr./94 Brasília, Instituto Nacional de Educação a Distância, p. 7-25.

PLASTINO, Carlos Alberto. O primado da efetividade: a crítica freudiana ao paradigma moderno. Rio de Janeiro: Relume Dumará, 2001.

PERIN, Marcelo Gattermann et al. A pesquisa survey em artigos de marketing nos EnAnpads da década de 90. In: XXIV Encontro dos Programas de Pós-Graduação em Administração, 2000, Florianópolis. Anais... Florianópolis: Anpad, 2000.

ROMANOWSKI, Joana Paulin; ENS, Romilda Teodora. As pesquisas denominadas do tipo "estado da arte" em educação. Diálogo Educ., v. 6, n. 19, p.37-50, set./dez. 2006.

SANTOS, Boaventura de Sousa. A critica da razão indolente: contra o desperdício da experiência. v. 1. São Paulo: Cortez, 2000.

SILVA, Anielson Barbosa; ROMAN NETO, João. Perspectiva multiparadigmática nos estudos organizacionais. In: GODOI, Christiane Kleinubing; BANDEIRA-DE-MELLO, Rodrigo; SILVA, Anielson Barbosa. Pesquisa qualitativa em estudos organizacionais: paradigmas, estratégias e métodos. São Paulo: Saraiva, 2006.

SOARES, M. B.; MACIEL, F. Alfabetização. Brasília: MEC/Inep/Comped, 2000.

TEIXEIRA, Paulo Marcelo Marini; MEGID NETO, Jorge. Investigando a pesquisa educacional: um estudo enfocando dissertações e teses sobre o ensino de Biologia no Brasil. Investigações em Ensino de Ciências, v. 11, p. 261-282, 2006.

VIEIRA, Francisco G. D. Por quem os sinos dobram? Uma análise da publicação científica na área de marketing do EnAnpad. In: XXII Encontro dos Programas de Pós-Graduação em Administração, 1998, Foz do Iguaçu. Anais... Foz do Iguaçu: Anpad, 1998.

. Ações empresariais e prioridades de pesquisa em marketing: tendências no Brasil e no mundo segundo a percepção dos acadêmicos brasileiros. In: XXIII Encontro dos Programas de Pós-Graduação em Administração, 1999, Foz do Iguaçu. Anais... Foz do Iguaçu: Anpad, 1999. 